\title{
Matrix metalloproteinase-8: a useful biomarker to refine the diagnosis of community-acquired pneumonia upon intensive care unit admission?
}

\author{
Fabrice Uhel ${ }^{1,2^{*}}$ D, Brendon P. Scicluna ${ }^{1,2}$, Lonneke A. van Vught ${ }^{1,2}$, Olaf L. Cremer ${ }^{3}$, Marc J. Bonten ${ }^{4,5}$,
} Marcus J. Schultz ${ }^{6}$ and Tom van der Poll ${ }^{1,2,7}$

Keywords: Sepsis, Pneumonia, Biomarker, Matrix metalloproteinase-8, Procalcitonin, Infection

The optimal management of severe community-acquired pneumonia (CAP) requires a prompt and accurate diagnosis [1]. Since clinical, radiological, and biological findings are poorly sensitive or specific, microbiological documentation often slow and unavailing, biomarkers could help to safely withhold antibiotics when the risk of bacterial infection is minimal and steer the diagnostic process towards non-infectious causes of respiratory failure [2]. In our previous study deriving the FAIM3:PLAC8 molecular biomarker, we noticed that $M M P 8$, encoding matrix metalloproteinase-8 (MMP-8), was the most overexpressed gene in confirmed CAP relative to non-infectious differential diagnoses (no-CAP) [3]. We investigated in the same cohort if plasma levels of MMP- 8 could be a valuable candidate biomarker for the diagnosis of CAP.

Similar to MMP8 whole blood gene expression (Fig. 1a), plasma MMP-8 (measured by Luminex assay [BioRad, Hercules, CA, USA]) was increased in patients with a suspicion of CAP compared to healthy volunteers and further increased in patients with confirmed CAP (median $3.45 \mathrm{ng} / \mathrm{mL}$; interquartile range [IQR], 0.93-

\footnotetext{
* Correspondence: f.uhel@amc.uva.nl

This comment refers to the article available at https://doi.org/10.1186/ s13054-016-1442-y

${ }^{1}$ Center of Infection and Immunity Amsterdam (CINIMA), Amsterdam University Medical Centers, location Academic Medical Center, University of Amsterdam, Amsterdam, The Netherlands

${ }^{2}$ Center for Experimental and Molecular Medicine, Amsterdam University Medical Centers, location Academic Medical Center, University of Amsterdam, Amsterdam, The Netherlands

Full list of author information is available at the end of the article
}

$15.40 \mathrm{ng} / \mathrm{mL}, n=86)$ compared to no-CAP $(0.76 \mathrm{ng} / \mathrm{mL}$; IQR, $0.35-2.64 \mathrm{ng} / \mathrm{mL}, p<0.001, n=31$, Fig. 1b). $M M P 8$ expression correlated with plasma levels of MMP-8 (rho $=0.73, p<0.001$, Fig. 1c). The receiver operating characteristic area under the curve (AUC) of plasma MMP-8 for the prediction of infection was 0.71 (95\% CI 0.59-0.81) (Fig. 1d). A numerical threshold set at 0.25 $\mathrm{ng} / \mathrm{mL}$ to minimize the risk of false-negative diagnosis allowed the identification of infection with a $97 \%$ sensitivity at the expense of a low specificity (19\%). AUCs for plasma MMP-8, MMP8 expression, and procalcitonin (widely used for the diagnosis of CAP [4]) were not statistically different (Fig. 1d). In the independent validation cohort comprising $57 \mathrm{CAP}$ and 26 no-CAP patients, the AUC for MMP-8 was 0.83 (95\% CI 0.73-0.91, Fig. 1e). A numerical threshold of $0.30 \mathrm{ng} / \mathrm{mL}$ favoring a $>97 \%$ sensitivity yielded a specificity of $15 \%$. The combination of MMP-8 (cutoff $0.25 \mathrm{ng} / \mathrm{mL}$ ) with a reference model including variables routinely used for the diagnosis of infection (body temperature $\geq 37.5^{\circ} \mathrm{C}$ and procalcitonin $>1.0 \mathrm{ng} / \mathrm{mL}$ [5]) significantly but modestly improved the prediction of infection (net reclassification improvement 0.36 [95\% CI 0.03-0.70], $p=0.033$ ).

In conclusion, MMP-8 slightly improved patient classification compared to a routine care reference strategy. However, its poor specificity precludes its use as a standalone diagnostic biomarker to safely withhold antibiotics in this critically ill population. Further studies are needed to establish the potential add-on value of plasma MMP-8 in diagnostic tests including multiple biomarkers.

(c) The Author(s). 2019 Open Access This article is distributed under the terms of the Creative Commons Attribution 4.0 International License (http://creativecommons.org/licenses/by/4.0/), which permits unrestricted use, distribution, and reproduction in any medium, provided you give appropriate credit to the original author(s) and the source, provide a link to the Creative Commons license, and indicate if changes were made. The Creative Commons Public Domain Dedication waiver (http://creativecommons.org/publicdomain/zero/1.0/) applies to the data made available in this article, unless otherwise stated. 


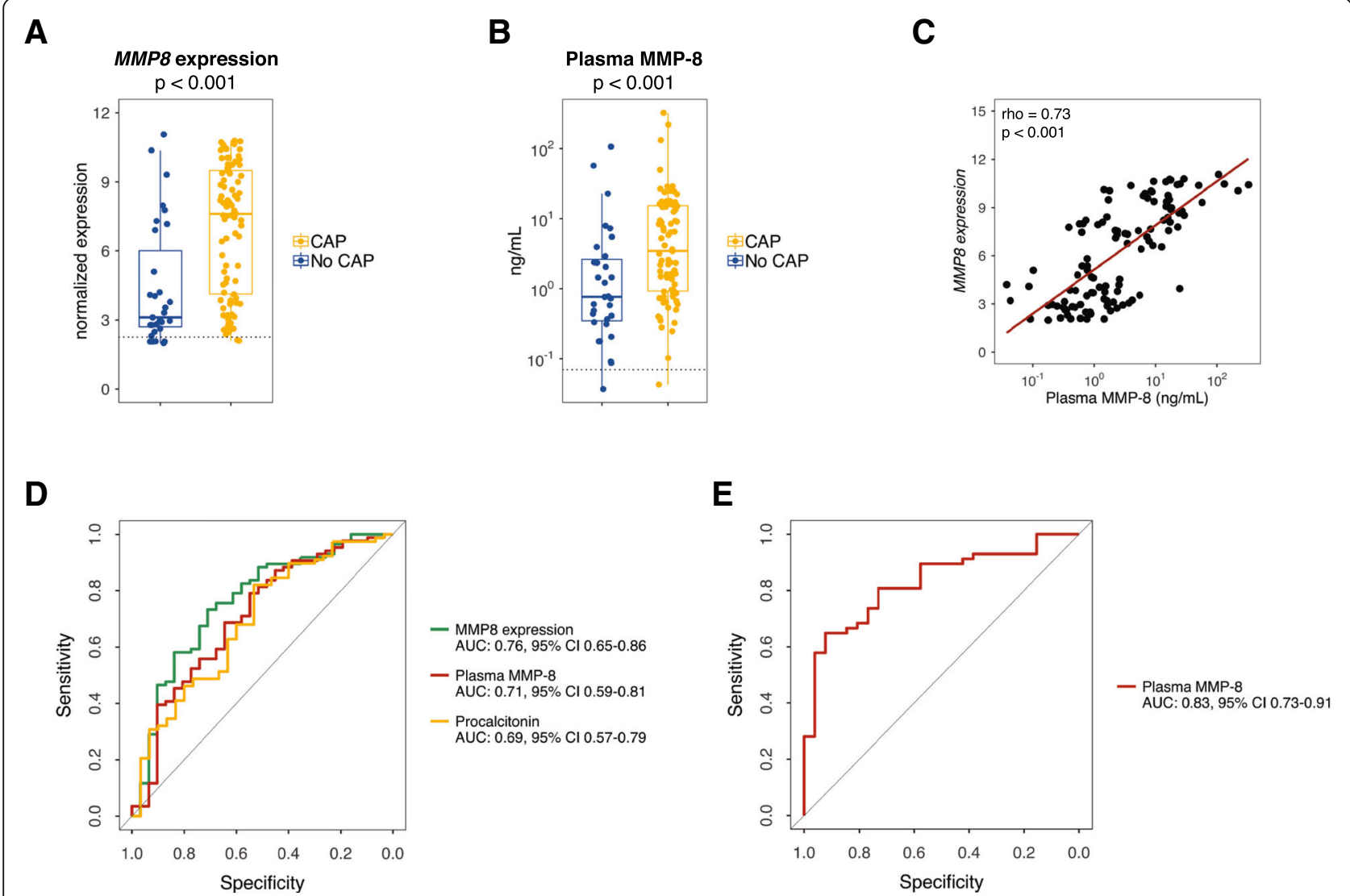

Fig. 1 Comparison of MMP8 expression, MMP-8 plasma levels, and procalcitonin in consecutively enrolled patients treated for suspected communityacquired pneumonia (CAP) upon intensive care unit admission. a Box-and-whisker and dot plots depicting MMP8 expression in CAP ( $n=86$ ) and noCAP patients (non-infectious control, $n=31$ ). The dotted line represents MMP8 median expression in age-matched healthy volunteers $(n=42)$. $\mathbf{b}$ Boxand-whisker and dot plots depicting MMP-8 plasma levels in CAP and no-CAP patients. The dotted lines indicate median values obtained in 27 agematched healthy subjects. c Correlation between MMP8 expression and MMP8 plasma levels in patients admitted for a suspected CAP. $\mathbf{d}$ Comparison of MMP8 expression or plasma levels with procalcitonin in patients consecutively admitted to the ICU for a suspicion of CAP (cohort A). Receiver operating characteristic analysis. AUC, area under the curve. e Assessment of the MMP8 plasma biomarker in an independent cohort (Validation cohort) of CAP $(n=57)$ and no-CAP patients $(n=26)$. Receiver operating characteristic analysis AUC

\section{Abbreviations}

AUC: Area under the curve; CAP: Community-acquired pneumonia; IQR: Interquartile range; MMP-8: Matrix metalloproteinase-8; ROC: Receiver operating characteristic

\section{Acknowledgements}

The authors acknowledge all the members of the Molecular Diagnosis and Risk Stratification of Sepsis consortium for the participation in the data collection and especially acknowledge Friso M. de Beer, M.D.; Lieuwe D. J. Bos, Ph.D.; Gerie J. Glas, M.D.; Roosmarijn T. M. van Hooijdonk, M.D., Ph.D.; Janneke Horn, M.D., Ph.D.; Laura R. A. Schouten, M.D.; Marleen Straat, M.D. Luuk Wieske, M.D., Ph.D.; Esther Witteveen, M.D. (Department of Intensive Care, Academic Medical Center, University of Amsterdam, The Netherlands), Arie J. Hoogendijk, Ph.D.; Mischa A. Huson, M.D.; Maryse A. Wiewel, M.D. (Center for Experimental and Molecular Medicine, and Center of Infection and Immunity Amsterdam (CINIMA), Amsterdam University Medical Centers, location Academic Medical Center, University of Amsterdam, Amsterdam, The Netherlands), Peter M.C. Klein Klouwenberg, M.D., Ph.D; David S.Y. Ong, M.D., Ph.D. (Department of Medical Microbiology, Department of Intensive Care Medicine, and Julius Center for Health Sciences and Primary Care, University Medical Center Utrecht, Utrecht, the Netherlands), Jos F. Frencken, M.D.; Maria E. Koster-Brouwer, MSc; Kirsten van de Groep, M.D.; and Diana M. Verboom, M.D. (Department of Intensive Care Medicine and Julius Center for Health Sciences and Primary Care, University Medical Center Utrecht, Utrecht, the Netherlands).

\section{Authors' contributions}

FU, BPS, and TvdP designed the paper and wrote the manuscript. All authors participated in collecting and analyzing the data. All authors read and approved the final version of the manuscript.

\section{Authors' information}

Not applicable

\section{Funding}

This research was performed within the framework of the Center for Translational Molecular Medicine (CTMM) (www.ctmm.nl) project Molecular Diagnosis and Risk Stratification of Sepsis (grant 04I-201). The sponsor CTMM was not involved in the design and conduction of the study nor was the sponsor involved in the collection, management, analysis, and interpretation of the data or preparation, review, or approval of the article. The decision to submit the article was not dependent on the sponsor.

\section{Availability of data and materials}

Gene expression datasets are available at the Gene Expression Omnibus public repository of NCBI under accession number GSE65682. Other data generated and/or analyzed during the current study are available from the corresponding author on reasonable request. 


\title{
Ethics approval and consent to participate
}

Patients were included via an opt-out consent method approved by the institutional review boards of both hospitals (Academic Medical Center

Amsterdam; University Medical Center Utrecht, Utrecht, IRB No. 10-056C).

\section{Consent for publication}

\author{
Not applicable
}

\section{Competing interests}

The authors declare that they have no competing interests.

\section{Author details}

${ }^{1}$ Center of Infection and Immunity Amsterdam (CINIMA), Amsterdam University Medical Centers, location Academic Medical Center, University of Amsterdam, Amsterdam, The Netherlands. ${ }^{2}$ Center for Experimental and Molecular Medicine, Amsterdam University Medical Centers, location Academic Medical Center, University of Amsterdam, Amsterdam, The Netherlands. ${ }^{3}$ Department of Intensive Care Medicine, University Medical Center Utrecht, Utrecht, the Netherlands. ${ }^{4}$ Department of Medical Microbiology, University Medical Center Utrecht, Utrecht, the Netherlands. ${ }^{5}$ Julius Center for Health Sciences and Primary Care, University Medical Center Utrecht, Utrecht, the Netherlands. ${ }^{6}$ Department of Intensive Care Medicine, Amsterdam University Medical Centers, location Academic Medical Center, University of Amsterdam, Amsterdam, The Netherlands. ${ }^{7}$ Division of Infectious Diseases, Amsterdam University Medical Centers, location Academic Medical Center, University of Amsterdam, Amsterdam, The Netherlands.

Received: 25 May 2019 Accepted: 10 June 2019

Published online: 20 June 2019

\section{References}

1. Prina $\mathrm{E}$, Ceccato $\mathrm{A}$, Torres $\mathrm{A}$. New aspects in the management of pneumonia. Crit Care. 2016;20:267.

2. Christ-Crain M, Opal SM. Clinical review: the role of biomarkers in the diagnosis and management of community-acquired pneumonia. Crit Care. 2010;14:203.

3. Scicluna BP, Klein Klouwenberg PMC, van Vught LA, Wiewel MA, Ong DSY Zwinderman AH, et al. A molecular biomarker to diagnose community-acquired pneumonia on intensive care unit admission. Am J Respir Crit Care Med. 2015; 192:826-35.

4. Schuetz P, Wirz Y, Mueller B. Procalcitonin testing to guide antibiotic therapy in acute upper and lower respiratory tract infections. JAMA. 2018;319:925-6.

5. Musher DM, Roig IL, Cazares G, Stager CE, Logan N, Safar H. Can an etiologic agent be identified in adults who are hospitalized for communityacquired pneumonia: results of a one-year study. J Infect. 2013;67:11-8.

\section{Publisher's Note}

Springer Nature remains neutral with regard to jurisdictional claims in published maps and institutional affiliations. 